\title{
PENGARUH KUALIFIKASI PENDIDIKAN TERHADAP PENEMPATAN KERJA APARATUR SIPIL NEGARA (ASN)
}

\author{
Mujiati Fatmawati ${ }^{1}$, Sekolah Tinggi Ilmu Sosial Politik Wira Bhakti, \\ fatmawatikesiman@gmail.com \\ Anak Agung Putu Sugiantiningsih ${ }^{2}$, Sekolah Tinggi Ilmu Sosial Politik Wira Bhakti, \\ gektien@gmail.com \\ Ronald Umbas ${ }^{3}$, Sekolah Tinggi Ilmu Sosial Politik Wira Bhakti, \\ ronaldumbas1@gmail.com
}

Vol. 35 No. 1 (2021): p 25-36

Submitted: March 28 nd, 2021 Accepted: May 28 ${ }^{\text {th }}, 2021$

Keywords:

Civil Apparatus

\begin{tabular}{l} 
Abstract \\
\hline Effective and efficient governance is demanded in this competitive \\
globalization era. Work performance of bureaucrats that still does not \\
meet people's expectation is still experienced by the people. That \\
problem can be reduced by the implementation of the ministerial \\
regulation on civil servants and bureaucratic reform \\
number:Kep/33/M.PAN/7/2011. It regulates the placement of civil \\
servants and has been applied by the Office for Housing Facilities \\
Bali Province. Its bureaucrats were placed in the positions according \\
to their knowledge, educational background, and expertise and skills \\
so that they work and serve the people better. The writer used \\
perspctective qualitative approach to identify the phenomenon. \\
Primary and secondary data were collected through observation and \\
interview, and analysed with interactive data analysis technique \\
(Miles, M.B, Huberman, A.M, dan Saldana, 2014). Based on the \\
analysis, it can be concluded that the indicators that were used to \\
assign a civil servant in a certain position in this office were \\
knowledge, skills, and expertise.
\end{tabular}




\begin{tabular}{ll} 
Abstrak \\
\hline Kata kunci: & Kinerja para birokrat sangat penting dalam memberikan \\
pelayanan kepada masyarakat. Profesionalisme mereka \\
semakin dituntut oleh masyarakat yang semakin kritis dan \\
oleh era globalisasi yang mengharuskan setiap orang bekerja \\
dengan cepat dan tepat. Implementasi Peraturan Menteri \\
Pendayagunaan Aparatur Negera dan Reformasi Birokrasi \\
Nomor:Kep/33/M.PAN/7/2011 tanggal 7 Juli 2011 tentang \\
pedoman Analisis Jabatan adalah salah satu hal mendasar \\
untuk mewujudkan kinerja birokrat yang sesuai tuntutan \\
jaman. Penempatan sumber daya aparatur sipil negara (ASN) \\
yang diterapkan pada Balai Prasarana Permukiman Wilayah \\
Bali, yang telah menerapkan penempatan sumber daya \\
manusianya yang sesuai seperti posisi jabatan kepala bidang \\
maupun kepala seksi yang memenuhi standar kompetensi. \\
Penempatan tersebut harus dilakukan berdasarkan latar \\
belakang pendidikan, keahlian atau keterampilan, dan \\
pengalaman. Dalam penelitian kualitatif ini, penulis \\
menggunakan mengumpulkan data primer dan sekunder \\
dengan melakukan observasi dan wawancara. Data yang \\
terkumpul dianalisis dengan teknik analisis interaktif (Miles, \\
Hubernam, and Saldana 2014). Dari riset yang sudah \\
dilaksanakan, penulis menyimpulkan bahwa kualifikasi \\
pendidikan belum berpengaruh pada penempatan Aparatur \\
Sipil Negara (ASN) di Kantor Balai Prasarana Permukiman \\
Wilayah Bali. \\
\hline
\end{tabular}

\section{PENDAHULUAN}

Memiliki sumber daya manusia yang mempunyai produktivitas dan kinerja tinggi adalah keinginan semua lembaga pemerintah agar dapat memberikan pelayanan yang prima kepada masyarakat. Dalam rangka melaksanakan tugas dan fungsinya, pemerintah sebagai pemberi pelayanan kepada publik di era globalisasi saat ini dipandang perlu untuk melakukan penempatan aparatur sipil negara (ASN) secara tepat. Hal ini sangat penting dilakukan agar pemberian pelayanan prima kepada masyarakat dapat terwujud. Pelayanan prima ini bertujuan agar waktu, tenaga, dan uang masyarakat tidak terbuang percuma karena pelayanan ASN yang lambat dan tidak akurat. Jika hal ini terus terjadi, pembangunan nasional pasti terganggu atau bahkan terhambat karena kinerja masyarakat baik sebagai karyawan atau wiraswastawan terganggu oleh pelayanan ASN yang tidak baik. Sebagai contoh, pelayanan untuk pengurusan kartu keluarga (KK) yang tidak baik menyebabkan 
seseorang kesulitan membeli nomor handphone baru yang sangat penting bagi pekerjaannya sehari-hari.

Untuk menunjang pembangunan nasional, ASN harus bekerja secara maksimal sesuai ilmu yang mereka dapat saat mengenyam pendidikan formal, serta keterampilan dan pengalaman mereka. Tentu para ASN juga harus memiliki dedikasi yang tinggi dalam memberikan pelayanan kepada masyarakat karena sesungguhnya mereka adalah pelayan masyarakat. Peraturan Pemerintah Nomor 13 Tahun 2002 Tentang perubahan atas Peraturan Pemerintah Nomor 100 Tahun 2000 tentang pengangkatan pegawai negeri sipil dalam jabatan struktural, menyatakan bahwa “untuk mewujudkan tujuan pembangunan nasional, diperlukan pegawai negeri sipil yang netral, mampu menjaga persatuan dan kesatuan bangsa, profesional, dan bertanggung jawab dalam melaksanakan tugas serta penuh kesetiaan dan ketaatan kepada pancasila, Undang-Undang Dasar 1945, Negara dan Pemerintah Republik Indonesia". Dengan peraturan ini, maka semakin kuat dasar untuk menempatkan ASN pada posisi atau jabatan yang tepat sesuai dengan latar belakang pendidikan, keahlian atau keterampilan, dan pengalamannya. Dengan kata lain, penempatan aparatur sipil negara harus didasarkan pada prinsip "the right man on the right place and the right man on the right job" (penempatan orang yang tepat pada tempat yang tepat dan untuk pekerjaan yang tepat (Hasibuan, 2011) (Hasibuan, 2011:63).

Dalam Peraturan Menteri Pendayagunaan Aparatur Negara dan Reformasi Birokrasi Nomor:Kep/33/M.PAN/7/2011 tanggal 7 Juli 2011 tentang pedoman Analisis Jabatan, terdapat penjelasan mengenai persyaratan yang harus dipenuhi ASN untuk memegang amanah memimpin atau memegang suatu jabatan. Dengan penempatan yang baik dan berdasarkan aturan ini, diharapkan pemerintah dapat memberikan pelayanan yang baik pula kepada masyarakat melalui para aparatur sipil negara yang memiliki nasionalisme dan bekerja secara professional.

Terkait dengan sumber daya manusia dan penempatan ASN pada posisi jabatan tertentu ini, penulis tertarik melakukan penelitian untuk mengetahui pengaruh kualifikasi pendidikan terhadap penempatan kerja aparatur sipil negara (ASN) pada Kantor Balai Prasarana Permukiman Wilayah Bali. Kantor ini bertugas dalam hal penyediaan sarana dan prasarana permukiman wilayah Bali dan telah melakukan 
penempatan sumber daya manusianya, contohnya sebagai kepala bidang dan kepala seksi, sebagai usaha melaksanakan tugas yang diberikan.

\section{METODE PENELITIAN}

Penelitian ini dilakukan dengan metode penelitian kualitatif yaitu sebuah penelitian di mana peneliti menganalisis data yang didapat dengan menggunakan beberapa metode Denzin dan Lincoln (dalam (Moleong, 2010)). Penelitian ini dilakukan di Kantor Balai Prasarana Permukiman Wilayah Bali yang berada di Jalan Danau Tamblingan Nomor: 49 Komplek PU Werdhapura Sanur Denpasar. Instansi ini memiliki wewenang melakukan penyediaan sarana dan prasarana permukiman di wilayah Bali. Penelitian ini dilakukan di Kantor Balai Prasarana Permukiman Wilayah Bali dikarenakan penulis bekerja di lokasi penelitian, sehingga mempermudah penulis mencari data penelitian yang dibutuhkan. Untuk mendapatkan data yang diperlukan, penulis mencari informasi dari informan yang pengalaman dan pengetahuannya berkaitan dengan tujuan penelitian. Informan tentu sangat penting dalam sebuah wawancara karena dalam wawancara, peneliti mendapatkan informasi yang memang diperlukan (Alwasilah, 2012). Seorang informan harus benar-benar tahu tentang halhal yang ditanyakan atau pelaku yang terlibat langsung dengan permasalahan penelitian.

\section{Daftar Informan}

\begin{tabular}{ll}
\hline Jabatan Informan & Nama Informan \\
\hline Kasubag Tata Usaha & A.A. Ngurah Budi Arnaya, ST \\
Pengadministrasi Umum & I Ketut Gede Ariambawa, \\
Penata BMN & SE,.M.H \\
Penyusun Monev dan Pelaporan & I Ketut Arsana, S.IP \\
Jafung TPL Pertama/ Penelaah PBL & Kristiningsih, S.Kom \\
Petugas Teknik & Agung Stiawan, ST . MT \\
Pengolah Monev dan Pelaporan & Putu Ari Gayatri, ST.MT \\
& I Nengah Surya Dharmajaya, SS \\
\hline
\end{tabular}

Sumber : Wawancara 
Teknik pengumpulan data yang digunakan dalam menyusun penelitian ini meliputi beberapa tahapan metode dalam pengumpulan data seperti Data Primer dan Sekunder. Data primer dikumpulkan melalui observasi di lapangan di mana penulis dapat mengamati suatu kegiatan yang dilakukan. Saat melakukan wawancara, penulis tidak saja memberikan pertanyaan tentang hal-hal yang telah dilakukan tapi juga meminta pihak yang diwawancara memberikan pendapatnya yang berkaitan dengan sumber daya manusia dan penempatan ASN. Wawancara seperti ini dilakukan agar penulis dan informan bersikap lebih terbuka dalam memberikan informasi sehingga data yang didapat lebih komprehensif (Sugiyono, 2003).

Data Sekunder meliputi hal-hal terkait objek secara teoritis dan ilmiah. Data sekunder pada penelitian ini adalah data-data pendukung berupa dokumen, laporan, atau buku. Penelitian Pengaruh Kualifikasi Pendidikan Terhadap Penempatan Kerja Aparatur Sipil Negara (ASN) ini menggunakan teknik analisis data interaktif (Miles, Hubernam, dan Saldana 2014). Adapun instrument bantu yang digunakan dalam penelitian ini adalah alat perekam, alat fotografi, dan dokumen-dokumen yang berkaitan dengan masalah penelitian dan alat bantu lainnya. Instrumen tersebut membantu peneliti melakukan verifikasi atau kesimpulan yang lebih konkrit atau valid terhadap fenomena yang dikaji.

\section{HASIL PENELITIAN}

Saat ini Direktorat Jenderal Cipta Karya sedang menjalani transformasi organisasi yang membutuhkan penyesuaian di berbagai aspek, termasuk pengelolaan data dalam rangka pengawasan dan pengendalian proses pembangunan infrastruktur permukiman.

Berkenaan dengan hal tersebut, Sekretariat Direktorat Jenderal Cipta Karya memiliki tugas pokok yaitu memberikan pelayanan teknis dan administrasi kepada semua unsur di lingkungan Direktorat Jenderal Cipta Karya. Dari tugas pokok tersebut Sekretariat ini melaksanakan pengelolaan 4 unsur manajemen yaitu, Sumber Daya Manusia(man), Keuangan(money), Bahan dan Peralatan(material), dan Metode(method) yang merupakan unsur utama organisasi. Unsur-unsur tersebut harus dilaksanakan dengan baik agar sebuah organisasi dapat berjalan dengan baik 
pula.

Direktur Keterpaduan Infrastruktur Permukiman yang diwakili oleh Kepala Sub Direktorat Pengelolaan Data dan Sistem Informasi Sri Murni Edi mengungkapkan, Balai Prasarana Permukiman Wilayah (BPPW) yang baru dibentuk di seluruh provinsi di Indonesia diharapkan dapat menyajikan data yang valid dan update untuk pengambilan keputusan pimpinan secara cepat dan tepat.

Struktur Organisasi

Balai Prasarana Permukiman Wilayah Bali

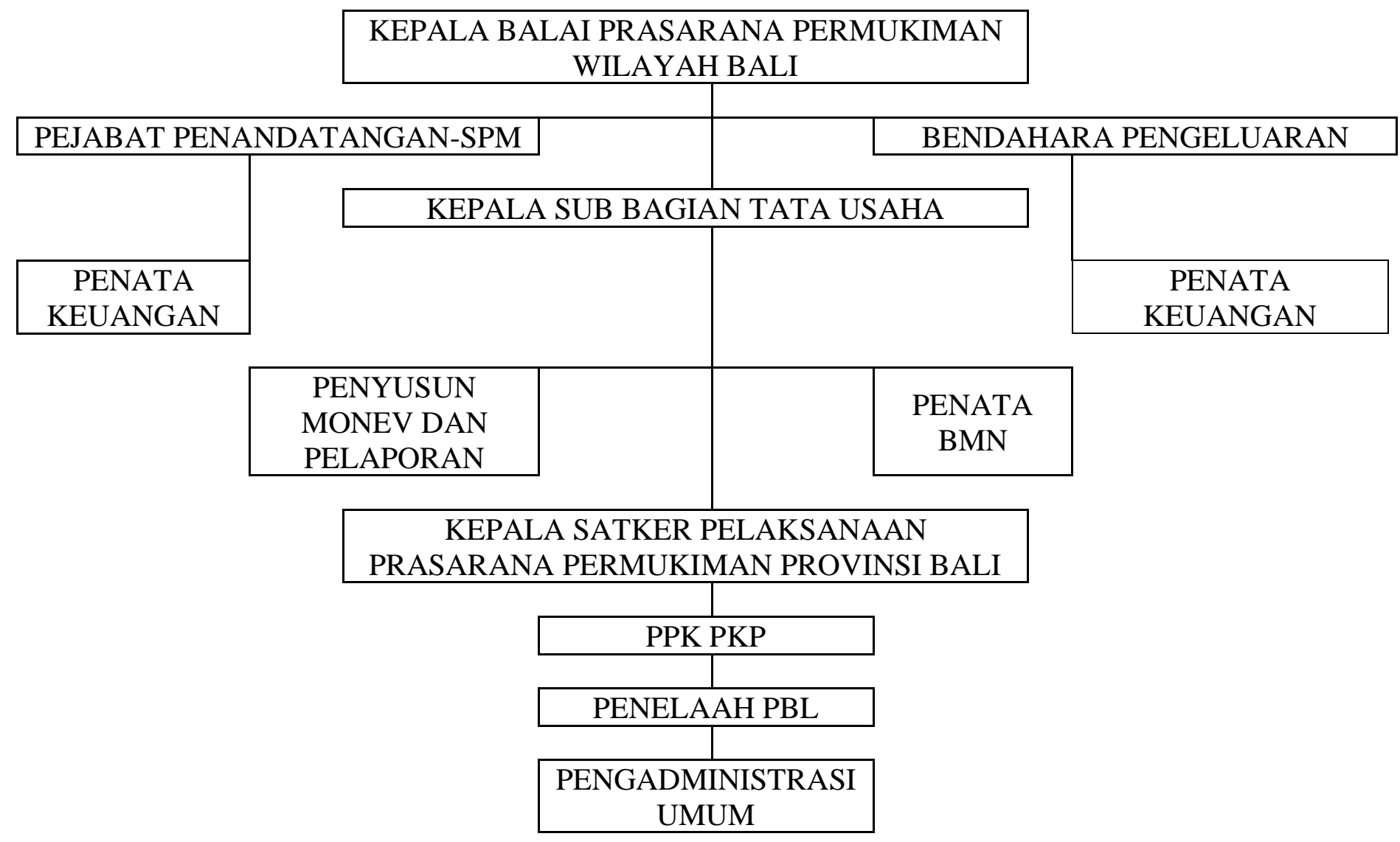

Sumber: Arsip Balai Balai Prasarana Permukiman Wilayah Bali 
Keadaan pegawai Balai Balai Prasarana Permukiman Wilayah Bali, menurut :

1) Kelamin

\begin{tabular}{ccc}
\hline Keterangan & Jumlah & Total \\
\hline Laki - laki & 77 orang & 125 orang \\
Perempuan. & 48 orang &
\end{tabular}

Sumber: Balai Balai Prasarana Permukiman Wilayah Bali

2) Tingkat Pendidikan

\begin{tabular}{ccc}
\hline Keterangan & Jumlah & Total \\
\hline SD & 1 orang & \\
SLTP & 2 orang & \\
SLTA & 38 orang & \\
D3 & 3 orang & \\
S1 & 68 orang & 125 orang \\
S2 & 13 orang &
\end{tabular}

Sumber:Balai Balai Prasarana Permukiman Wilayah Bali 3) Status Pegawai

\begin{tabular}{ll}
\hline \multicolumn{1}{c}{ Jabatan } & Status Kepegawaian \\
\hline PPK Pengembangan PLP & PNS Pusat \\
Penelaah PLP & PNS Pusat \\
Penelaah PLP & PNS Pusat \\
Penata Teknik PLP & PNS Pusat \\
Petugas Teknik & Non PNS Substansi \\
Petugas Teknik & Non PNS Substansi \\
Petugas Teknik & Non PNS Substansi \\
Petugas Teknik & Non PNS Substansi \\
Penata Keuangan & PNS Pusat \\
Pengadministrasi Umum & Non PNS Substansi \\
Petugas Kebersihan & Non PNS Pendukung \\
Pengemudi & Non PNS Pendukung \\
\hline
\end{tabular}


Sumber:Balai Prasarana Permukiman Wilayah Bali

4) Usia

\begin{tabular}{lll}
\hline Keterangan & Jumlah & Total \\
\hline $23-30$ Thn & 6 orang & \\
$31-35$ Thn & 22 orang & \\
$36-40$ Thn & 22 orang & \\
$41-45$ Thn & 15 orang & \\
$46-50$ Thn & 27 orang & 125 orang \\
$50-57$ Thn & 23 orang &
\end{tabular}

Sumber: Balai Prasarana Permukiman Wilayah Bali

Data Investaris Barang Peralatan Kantor

Balai Prasarana Permukiman Wilayah Bali

\begin{tabular}{lcc}
\hline \multicolumn{1}{c}{ Jenis } & Jumlah & Kondisi \\
\hline PC Unit & 97 & 93 Baik, 4 Rusak Ringan \\
Laptop & 62 & 44 Baik, 4 Rusak Ringan, 15 Rusak Berat \\
Printer & 65 & 57 Baik, 3 Rusak Ringan, 5 Rusak Berat \\
Handy Talky & 4 & Baik \\
Kamera Digital & 9 & 3 Baik, 3 Rusak Ringan, 3 Rusak Berat \\
Lensa Kamera & 1 & Baik \\
Tripod Kamera & 1 & Baik \\
Tab & 1 & Baik \\
Drone & 2 & Baik \\
LCD Projector/Infocus & 4 & 2 Baik, 1 Rusak Ringan, 1 Rusak Berat \\
Handy Cam & 5 & 3 Baik, 2 Rusak Berat \\
Uninterruptible Power Supply (UPS) & 6 & Baik \\
GPS Mapper Counter & 7 & 5 Baik, 2 Rusak Ringan \\
Gateway ZX 6960 & 1 & Baik \\
Lemari Penyimpan & 30 & Baik \\
Lemari Besi/Metal & 12 & Baik \\
Lemari Kayu & 118 & Baik \\
\hline & &
\end{tabular}




\begin{tabular}{|c|c|c|}
\hline Lemari Besi Arsip & 3 & Baik \\
\hline Lemari Kayu Kecil & 9 & Baik \\
\hline Lemari Kayu Besar & 4 & Baik \\
\hline Lemari Arsip dorong Besi & 3 & Baik \\
\hline Lemari Besi & 8 & 1 Rusak Ringan, 4 Rusak Berat \\
\hline Lemari Kaca & 3 & Baik \\
\hline Lemari Display & 1 & Baik \\
\hline Rak Kayu & 25 & Baik \\
\hline Rak Kaca Besar & 1 & Baik \\
\hline Rak Besi & 17 & Baik \\
\hline Filing Cabinet Kayu & 4 & Baik \\
\hline Filling Cabinet & 18 & Baik \\
\hline Brandkas & 2 & Baik \\
\hline Buffet & 21 & Baik \\
\hline Laci kayu & 14 & Baik \\
\hline Meja Kerja Kayu & 79 & 2 Rusak Ringan \\
\hline Meja Rapat & 2 & Baik \\
\hline Meja Komputer & 7 & Baik \\
\hline Meja Kerja Kaca & 2 & Baik \\
\hline Meja Rapat Kayu & 1 & Baik \\
\hline Meja Printer Kayu & 5 & Baik \\
\hline Meja Resepsionis Kayu & 1 & Baik \\
\hline Meja Tamu Kayu & 1 & Baik \\
\hline Kursi Besi/Metal & 155 & 4 Rusak Ringan, 2 Rusak Berat \\
\hline Kursi Kayu & 19 & Baik \\
\hline Kursi Dorong & 9 & 3 Rusak Berat \\
\hline Kursi & 33 & Baik \\
\hline Kursi Resepsionis Kayu & 1 & Baik \\
\hline Kursi Tamu Kayu & 4 & Baik \\
\hline Sofa Kayu & 4 & Baik \\
\hline
\end{tabular}




\section{PEMBAHASAN}

Indikator Pengaruh Penempatan Sumber Daya Aparatur Sipil Negara (ASN)

Pada Kantor Balai Prasarana Permukiman Wilayah Bali, antara lain:

1) Indikator Pengetahuan (latar belakang pendidikan, wawasan pengetahuan tentang pekerjaan)

I Ketut Arsana, S.IP (Penata BMN) menyatakan dirinya lambat dalam menyelesaikan pekerjaan dan memerlukan proses karena masih harus belajar. Sementara Kristiningsih, S.Kom (Penyusun Monev dan Pelaporan) menyampaikan pula dalam wawancaranya, bahwa dirinya merasakan dampaknya jika ketidaksesuaian ini terjadi.

2) Keterampilan (keterampilan secara teknis, keterampilan sosial, keterampilan konseptual)

Menurut I Ketut Arsana, S.IP (Penata BMN), menyampaikan, “jika pegawai tidak punya keterampilan itu lambat dalam menyelesaikan pekerjaanm pegawai tersebut masih harus belajar. Pekerjaan pun bisa selesai sampai dengan 1 bulan, bahkan terlambat dalam pelaksanaan perlu waktu untuk belajar. Karena keterampilan tidak punya". Sedangkan menurut Kristiningsih, S.Kom (Penyusun Monev dan Pelaporan), walaupun kualifikasi pendidikan kita tidak sesuai, tapi kalau kita punya keterampilan, pasti kita bisa beradaptasi dengan cepat. Sementara Agung Setiawan, ST . MT (Jafung TPL Pertama/ Penelaah PBL), berpendapat bahwa kepekaan seseorang pegawai diperlukan untuk mengetahui dan mempelajari karakteristik tugas yang diemban. Itu merupakan salah satu keterampilan. Jadi kita pun dapat menyesuaikan dengan cepat.

3) Kemampuan (kemampuan yang dimiliki untuk menyelesaikan pekerjaannya, kepribadian, minat untuk bekerja) ditambah pula dengan bakat kerja serta tanggung jawab terhadap pekerjaan

Berdasarkan hasil wawancara pada tanggal 10 Januari 2020 dengan A.A. Ngurah Budi Arnaya, ST (Kasubag Tata Usaha) menyampaikan bahwa: “Sistem penempatan dilakukan melalui pertimbangan tingkat kebutuhan jabatan sesuai kualifikasi pendidikan yang dilakukan Kepala Balai sebagai pimpinan tertinggi di kantor Balai Prasarana Permukiman Wilayah Bali. Untuk jabatan tertentu penempatan 
dilakukan melalui SK Kementerian Pekerjaan Umum dan Perumahan Rakyat . Diantaranya jabatan Kepala Balai Prasarana Permukiman Wilayah Bali, Kepala Tata Usaha Balai Prasarana Permukiman Wilayah Bali, Pejabat Pembuat Komitmen (PPK), Bendahara, dan Pejabat SPM".

Sedangkan menurut I Ketut Gede Ariambawa, SE,.M.H (Pengadministrasi Umum), menyampaikan efek daripada melakukan penempatan tidak sesuai kemampuannya Pengaruhnya tidak dapat menyelesaiakan tugas tepat waktu, butuh penyesuaian.

Dari hasil wawancara yang penulis lakukan pada informan yang ada di lingkungan Kantor Balai Prasarana Permukiman Wilayah Bali, dapat menulis simpulkan bahwa penempatan pegawai diharapkan sesuai dengan kualifikasi pendidikannya. Agar tidak membuang waktu dalam setiap tugas pada bidang baru yang tidak sesuai dengan kualifikasi pendidikannya. Akhirnya berdampak pada terhambatnya setiap deatline tugas yang diamanatkan atasan pada pegawainya.

\section{KESIMPULAN}

Kualifikasi Pendidikan Terhadap Penempatan Kerja Aparatur Sipil Negara (ASN) Pada Kantor Balai Prasarana Permukiman Wilayah Bali belum dilakukan penyesuaian dengan kualifikasi pendidikan. Pimpinan badan hanya menerima pegawai sesuai dengan mandat atasan. Walaupun penempatan pegawai belum dilakukan sesuai dengan kualifikasi pendidikan, Karena Pegawai yang diberi jabatan adalah pegawai ASN yang sudah ada sebelumnya dan penempatan adalah pemberdayaan ASN dan mekanisme kerja tetap terkontrol dengan baik. Walaupun situasi kerja dapat terlaksana, dengan konsekuensi yang dialami adalah lambatnya penyelesaian tugas oleh pegawai yang tidak sesuai kualifikasi pendidikannya, karena memerlukan waktu untuk adaptasi dalam pekerjaan. Diharapkan untuk kedepannya, pimpinan mengawasi dan memberikan solusi serta perhatian pada bidang-bidang yang penempatannya didominasi oleh pegawai yang kualifikasi pendidikannya tidak sesuai agar pegawai mendapatkan pelatihan yang maksimal sehingga terciptanya mekanisme kerja yang terkontrol dengan lebih baik. 


\section{DAFTAR PUSTAKA}

Alwasilah, A. C. (2012). Pokoknya Kualitatif: Dasar-Dasar Merancang dan Melakukan Penelitian Kualitatif: Dasar-Dasar Merancang dan Melakukan Penelitian Kualitatif (7th ed.). Bandung: PT Dunia Pustaka Jaya.

Hasibuan, M. S. . (2011). Manajemen Sumber Daya Manusia. Jakarta: . PT Bumi Askara.

Miles, M.B, Huberman, A.M, dan Saldana, J. (2014). Qualitative Data Analysis, A Methods Sourcebook (3rd ed.). Sage Publications.

Moleong, L. J. (2010). Metodologi Penelitian Kualitatif. Bandung: PT Remaja Rosdakarya.

Peraturan Menteri Pendayagunaan Aparatur Negara dan Reformasi Birokrasi Nomor:Kep/33/M.PAN/7/2011 tanggal 7 Juli 2011 tentang pedoman Analisis Jabatan.

Keputusan Kepala Badan Kepegawaian Negara Nomor 13 Tahun 2002 tentang Ketentuan Pelaksanaan Peraturan Pemerintah Nomor 100 Tahun 2000 sebagaimana telah diubah dengan Peraturan Pemerintah Nomor 13 Tahun 2002 tentang Pengangkatan Pegawai Negeri Sipil dalam Jabatan Struktural. 